\title{
Saúde e territorialização na perspectiva do desenvolvimento
}

\author{
Health and territorialization from the perpective of development
}

\author{
Carlos Augusto Grabois Gadelha ${ }^{1}$ \\ Cristiani Vieira Machado ${ }^{1}$ \\ Luciana Dias de Lima ${ }^{1}$ \\ Tatiana Wargas de Faria Baptista ${ }^{1}$
}

${ }^{1}$ Departamento de Administração e Planejamento em Saúde, Escola Nacional de Saúde Pública Sergio Arouca, Fundação Oswaldo Cruz. Rua Leopoldo Bulhões $1480,7^{\circ}$ andar, Manguinhos. 21041-210 Rio de Janeiro RJ. gadelha@ensp.fiocruz.br
Abstract The relationship between health and development is complex and lies in the field of political economy, given that it involves different social, political, and economic interests. In the Brazilian case, this association is particularly relevant in terms of the territorial dimension, in light of the central role of healthcare services in the organization of the urban network and the demarcation of territorial schedules and limits. In the theoretical-conceptual field, this study explores analytical areas that approach the relations between health and development, as well as between health and the territorial issue; and analyzes the history of the decentralization and regionalization policy in the Unified National Health System (SUS) and Federal investments that constitute the basis for its spatial evolution. Based on this conceptual review and empirical data, the study attempts to establish theoretical and political-institutional connections between health and development. The aim is thus to support the discussion on challenges facing a new role for health in the Brazilian development model, historically marked by economic and social inequalities with strong territorial overtones.

Key words Healthcare systems, Regional development, Investments in health, Unified Health System (SUS)
Resumo A relação entre saúde e desenvolvimento é complexa e remete ao campo da economia politica, dado que envolve diferentes interesses sociais, políticos e econômicos. No caso brasileiro, esta associação é particularmente relevante no que diz respeito à dimensão territorial, tendo em vista o papel central dos serviços de saúde para organização da rede urbana e delimitação de escalas e limites territoriais. No campo teórico-conceitual, o artigo explora vertentes analíticas das relações entre saúde e desenvolvimento, bem como entre a saúde e a questão territorial. A seguir, analisa a trajetória da política de descentralização e regionalização do Sistema Único de Saúde (SUS) e dos investimentos federais, que constituem a base de sua evolução espacial. A partir da revisão conceitual e dos dados empíricos, procuram-se estabelecer os nexos teóricos e político-institucionais entre saúde e desenvolvimento, buscando subsidiar a discussão dos desafios para uma nova inserção da saúde no modelo de desenvolvimento brasileiro, historicamente marcado por desigualdades econômicas e sociais com forte expressão territorial. Palavras-chave Sistemas de saúde, Desenvolvimento regional, Investimentos em saúde, SUS 


\section{Introdução}

Diversos campos de estudo já reconhecem o papel central da saúde nas concepções de desenvolvimento, inclusive na sua dimensão territorial, particularmente importante para um país com as características do Brasil. Contribuições teóricas recentes ${ }^{1,2}$ trouxeram à luz a integração da saúde ao conceito de desenvolvimento, sendo um dos fatores determinantes das condições de vida e bem-estar. O Índice de Desenvolvimento Humano (IDH), que é o indicador de referência mais utilizado nas análises comparativas do grau de desenvolvimento dos Estados nacionais, incorpora a saúde como um de seus três componentes. Entretanto, seria um reducionismo indesejável restringir a relação entre saúde e desenvolvimento a esta vertente do capital humano, uma vez que diversas são as relações entre os referidos campos.

Ressalta-se, no caso brasileiro, o papel da saúde como propulsor de desenvolvimento na sua dimensão regional, cuja importância pautase pelo marcante corte territorial das iniquidades socioeconômicas nacionais. A saúde, por ser central para a organização das redes urbanas, influenciando a delimitação de escalas e limites territoriais, é estruturante da ocupação territorial. Ademais, tem o potencial de definir novos fluxos de investimentos e, portanto, de reverter tendências tradicionais de concentração da produção e renda no espaço. A saúde constitui-se, assim, como um campo de particular relevância para a coesão social e econômica no território nacional. Ainda mais ao se considerar todos os segmentos do Complexo Econômico Industrial da Saúde que relaciona os segmentos produtivos ao de serviços - enfatiza-se seu potencial para a formação da infraestrutura econômica e social, dinamização econômica e organização social e institucional. Desta forma, a saúde relaciona-se, de forma inequívoca, a um conceito mais amplo de desenvolvimento, que pressupõe sua sustentabilidade.

Dito isto, a saúde deve ocupar papel de destaque nas estratégias políticas nacionais, podendo ser estimulada pelo aumento dos gastos nacionais e pelo incremento da eficácia e eficiência de suas ações, a partir de uma atuação efetiva do Estado. Nessa perspectiva, a saúde adquire um papel predominantemente técnico, vinculado à sua contribuição para um ambiente socioeconômico desenvolvido favorável para a vida das pessoas, em uma redução da política à administração ${ }^{3}$.

Vale enfatizar, todavia, que a relação entre saúde e desenvolvimento é complexa, caracteri- zada por um processo social e político que requer, para sua análise, uma aproximação ao campo da economia política, uma vez que estão envolvidos interesses diversos: sociais, econômicos, territoriais e políticos. Estes, em seu conjunto, geram conflitos distributivos, formas diversas de organização e pactuação entre atores, disputas pela priorização do orçamento público nos distintos níveis de governo e relações entre o Estado e o setor privado, para citar algumas dimensões da complexidade inerente a este sistema.

Esses conflitos fazem parte da configuração histórica do Estado Nacional e constituem a base dos processos de desenvolvimento e dos avanços sociais na área da saúde. Portanto, resumir a saúde a um elemento intrínseco ao desenvolvimento, pela vertente única do capital humano, é não assumir o importante papel que este campo ocupa nas economias dos países, de forma geral, e do Brasil especificamente. De forma análoga, tal reducionismo não permite relevar os conflitos de interesse e de poder em torno da questão, cuja falta de equilíbrio acaba, muitas vezes, determinando o desenvolvimento do sistema de saúde em desacordo das diretrizes e preceitos do SUS e dos objetivos de desenvolvimento em longo prazo no Brasil.

Este trabalho procura explorar os elos entre saúde e desenvolvimento, com foco na questão territorial, partindo da premissa analítica que o território é o espaço concreto da vida social no qual as políticas e estratégias públicas e privadas se encontram e mostram seu grau de convergência ou divergência. A importância desta análise particulariza-se ao se considerar que ainda não se desenvolveu, em âmbito nacional, um enfoque territorial/regional para o desenho de políticas de saúde, o que tem comprometido o atendimento das múltiplas realidades que se apresentam no território, assim como a superação, ou mesmo a mitigação, das desigualdades nele observadas. Busca-se ilustrar a complexidade dessas relações a partir da análise do caso brasileiro, considerando tanto o debate teórico quanto sua expressão em alguns âmbitos estratégicos da condução da política nacional de saúde.

Para tanto, esse artigo estrutura-se a partir da discussão de vertentes analíticas que abordam as relações entre saúde e padrões nacionais de desenvolvimento, bem como entre a saúde e a questão territorial. Em seguida, analisa-se a trajetória recente da política de saúde no Brasil com ênfase nos processos de descentralização e regionalização do Sistema Único de Saúde (SUS) e nos investimentos que constituem a base de sua evo- 
lução espacial. Por fim, retoma-se a discussão entre saúde e desenvolvimento, procurando estabelecer os nexos teóricos e político-institucionais que condicionam esta relação. Espera-se que tal análise possa iluminar a reflexão sobre os desafios colocados para uma nova inserção da saúde no modelo de desenvolvimento nacional, historicamente marcado por desigualdades socioeconômicas de forte expressão territorial.

\section{Saúde e desenvolvimento: desdobramentos para a questão territorial}

O interesse pela análise da relação entre os campos da saúde e desenvolvimento não é uma novidade. $\mathrm{Na}$ realidade, no campo teórico-conceitual, há distintas vertentes de análise que incorporam a saúde na sua relação com o desenvolvimento, compreendendo-a como:

(1) Componente essencial de qualidade de vida e de intervenção pública na área social. Desta forma, configura-se como uma dimensão privilegiada para a geração de bem-estar, promoção de equidade e de inclusão social ${ }^{4}$.

(2) Fator genérico que conforma o ambiente socioinstitucional indutor de crescimento econômico e de investimentos, captado em modelagens matemáticas nas teorias endógenas do crescimento que incorporam, por exemplo, a expectativa de vida ou o capital humano na função investimento ${ }^{5}$, em conjunto com outros fatores, como as atividades de pesquisa e desenvolvimento (P\&D) e a educação.

(3) Sistema complexo, dado que relaciona segmentos produtivos e de serviços sociais e que conforma uma fonte importante de geração de renda, emprego e inovação. Potencializa mudanças estruturais relacionadas à expansão dos novos paradigmas tecnológicos, em especial no contexto atual de globalização assimétrica e de profundas transformações de conhecimento decorrentes da revolução tecnológica, remetendo para uma abordagem de economia política de corte estruturalista ${ }^{6}$.

(4) Política fundamental na conformação dos sistemas de proteção social modernos, associando-se a movimentos de desmercantilização do acesso (e maior responsabilização social, por parte do Estado, sobre os riscos de morte e adoecimento das pessoas), mercantilização da oferta e acumulação de capital (formação do complexo econômico-industrial da saúde), que convivem de forma complexa e contraditória nos distintos sistemas de saúde ${ }^{7}$, em especial no Brasil, dado que a diretriz de universalização do Sistema estabeleceu-se com o mercado privado já consolidado e razoavelmente organizado, pautando as demandas tecnológicas e pressionando custos.

(5) Área que, ao mobilizar uma magnitude expressiva da renda e da riqueza dos países, reúne interesses diversos que acentuam a disputa pelo poder na definição das diretrizes políticas da saúde. A dimensão política da saúde refere-se aos conflitos existentes entre os que usam os serviços de saúde, aqueles que os proveem, os que pagam por eles e aqueles que os regulam ${ }^{8}$.

(6) Atividade que, pela sua natureza, envolve um arranjo político-institucional rico e complexo (ainda mais marcante quando se trata de países continentais federativos e democráticos, como o Brasil), envolvendo relações entre diferentes esferas de governo e com a sociedade civil, inerentes ao processo de desenvolvimento e a sua configuração territorial ${ }^{9}$. Note-se que, no Brasil, a primeira associação entre saúde e desenvolvimento, por parte do Estado, data da República Velha, quando a superação das péssimas condições de saúde e higiene nacionais foi entendida como condição sine qua non ao projeto político de construção de autoridade estatal sobre o território e conformação de uma ideologia de nacionalidade.

(7) Área importante e crítica para a geopolítica internacional, notadamente para a relação entre países fronteiriços, tendo papel cada vez mais destacado nas políticas voltadas para a integração de países de uma mesma região ou continente, como é o caso do Mercosul e da América do Sul ${ }^{10,11}$.

Cada uma dessas vertentes reforça, em maior ou menor grau, o argumento da saúde como uma área estratégica para o desenvolvimento no âmbito das diversas linhas ideológicas.

Na primeira vertente, ao se referir à qualidade de vida e não apenas à ausência de doenças, as ações em saúde remetem para o padrão nacional de desenvolvimento econômico e social. Aponta, assim, para a transversalidade da saúde, o que demanda tanto a ampliação dos esforços e dos investimentos setoriais quanto a confluência e articulação entre diversas políticas. A dimensão territorial do desenvolvimento se mostra necessária, condicionando e sendo condicionada pelas ações de saúde, uma vez que é no espaço, em suas diversas escalas, onde as políticas se encontram e podem gerar as sinergias necessárias ao processo de desenvolvimento. Planejar e implementar, de fato, a regionalização da saúde torna-se particularmente importante em contexto de globaliza- 
ção assimétrica, em que fluxos e interesses internacionais acomodam-se desigualmente no território. Isso acaba por pressionar e provocar uma separação entre a vertente social e a econômica do desenvolvimento da saúde e colocar em xeque princípios do SUS, provocando, como resultado, uma acentuação das assimetrias da globalização.

A vertente 2 apresenta a linha que considera a saúde como uma das variáveis da função de produção que explicam o crescimento econômico, medido pela renda per capita, a longo prazo. Em que pese uma série de divergências com este modelo (como a visão restrita da saúde e a despolitização do processo de desenvolvimento), ressalta-se que a saúde é vista como um dos fatores na raiz do desenvolvimento e da própria evolução da taxa de investimento ${ }^{5}$. Logo, o elo entre saúde e desenvolvimento é mais forte do que sua inserção como uma área essencial para aferição das condições de vida. Ou seja, as ações em saúde contribuem para o desenvolvimento regional tanto pelo seu componente de investimento quanto pelo impacto que exercem (nas despesas de capital e correntes) no contexto que determina os investimentos locais, regionais e nacionais. Assim, pode-se superar o ciclo vicioso do fluxo de investimentos no país que tem, historicamente, contribuído para perpetuar e acentuar as diferenças regionais observadas.

A vertente 3 retoma a abordagem estruturalista na sociedade contemporânea, caracterizada por processo assimétrico de globalização e pelo conhecimento e inovação como fatores determinantes das transformações estruturais e do dinamismo econômico. Nesta perspectiva, a saúde pode ser vista como um complexo econômico de atividades que está na raiz dos esforços públicos e privados nacionais voltados para a inovação e o desenvolvimento. O complexo econômico-industrial da saúde (CEIS) - que envolve a interação entre segmentos industriais e de serviços - tem potencial para alavancar áreas-chave da revolução tecnológica em curso (microeletrônica, biotecnologia, química fina, novos materiais, nanotecnologia, mecânica de precisão), sendo estratégico para o desenvolvimento das regiões e dos países e criando oportunidades de aliar a lógica econômica com a social ${ }^{6}$.

Segundo esta visão, que se assenta no reconhecimento da literatura recente de que a inovação é uma variável crítica para o desenvolvimento regional ${ }^{12}$, a configuração espacial da rede de saúde e os encadeamentos intersetoriais e institucionais que alavanca podem constituir uma base estruturante para dinamizar economias re- gionais e locais, tendo um impacto direto na geração de renda, na incorporação de trabalho qualificado e na evolução dos sistemas locais de inovação em saúde ${ }^{13}$. A contra face desta perspectiva é que, na ausência de uma visão estratégica que engendre trajetórias virtuosas, emergem, na área da saúde, os mesmos gargalos políticos e estruturais que bloqueiam ou restringem as economias nacionais periféricas, deixando vulnerável a área social e o próprio desenvolvimento nacional, regional e local.

A visão do complexo econômico-industrial da saúde é complementada pelas contribuições teóricas que localizam a saúde como uma política fundamental na conformação dos modernos sistemas de proteção social, bem como pelas contribuições que acentuam a dimensão política na configuração destes modelos, abordadas nas vertentes 4 e 5 . O que determina a expansão econômica deste setor é a estratégia política e a concepção de Estado e do próprio desenvolvimento que dá sustentação ao modelo. Assim, o crescimento acelerado de acumulação de capital das indústrias da saúde se efetiva num movimento mais abrangente que integra não só a demanda de serviços, insumos e produtos, mas também consolida um determinado modelo de intervenção do Estado na área social. $\mathrm{O}$ tratamento da saúde como o fator estruturante do modelo de proteção social ainda precisa avançar substancialmente, dado que políticas de desenvolvimento foram deixadas de lado em meio à liberalização da economia.

$\mathrm{Na}$ América do Sul, cada país experimentou de forma diferenciada o processo de constituição do complexo econômico da saúde, onde estiveram presentes, em maior ou menor grau, os fenômenos de desmercantilização do acesso (a saúde como direito) e mercantilização da oferta (assalariamento dos profissionais, formação de empresas médicas e intermediação financeira por meio de planos e seguros de saúde $)^{8}$. Nesse contexto, a configuração das ações e serviços de saúde no território apresenta-se como lócus privilegiado de análise da capacidade de intervenção socioeconômica do Estado, do modelo político e dos conflitos de interesse. No Brasil, embora novas estratégias e instrumentos estejam sendo implantados (observando-se ganhos de institucionalidade), ainda há um longo caminho para a articulação de políticas sociais e econômicas para a consolidação das regiões de saúde de forma sustentável, de modo que produzam alterações nas determinantes de desigualdade. Por ora, os interesses do capital continuam a pautar, preponderantemente, a dinâmica desses setores produtivos. 
A vertente 6, político-institucional, também aponta a importância da saúde na região, vista como um território vivo impregnado de arranjos socioprodutivos e institucionais ${ }^{14}$. A saúde, por constituir uma base de coesão política e institucional, deve ser articulada com as estratégias federativas de regionalização, da dimensão nacional à local. Uma vez mais, vale ressaltar, não houve atualização significativa das relações federativas entre as três esferas de governo, de modo a valorizar a regionalização no bojo das políticas de saúde; pelo contrário, a relação direta entre a União e municípios, sem o estabelecimento devido das unidades federadas como coordenadores das ações de saúde em seu território, tem dificultado uma articulação regional no processo de formulação e implementação das políticas.

A última vertente (7) refere-se à geopolítica da saúde no contexto da integração sul-americana. Em uma perspectiva que transcende a visão de segurança nacional, a Faixa de Fronteira, que representa quase 30\% do território nacional, passa a ser vista como uma região de desenvolvimento e integração entre os países da América do Sul, fazendo parte das escalas trabalhadas no esforço de regionalização em curso. Dentre as políticas públicas, a saúde tem sido destacada como um importante meio de promoção de ações cooperativas entre estados e municípios fronteiriços e no âmbito da estratégia nacional de aproximação política e econômica com os países do continente. Entretanto, dificuldades diversas quanto à priorização política desta região - afastada do centro político decisório nacional e de cada estado ao qual pertencem, e a consequente escassez de recursos para estes direcionados - e às questões diplomáticas e institucionais, para citar alguns exemplos, não têm permitido que na prática se alcancem resultados relevantes.

De toda forma, a partir dessas abordagens pode-se aprofundar os vínculos conceituais entre saúde e desenvolvimento na perspectiva territorial, com base na literatura que explora a temática do desenvolvimento regional ${ }^{12-15}$. No âmbito desses vínculos, o primeiro aspecto a ser ressaltado diz respeito ao papel dos serviços para a organização das redes urbanas, ao determinarem a capacidade de polarização das cidades. $\mathrm{Na}$ prática, o núcleo urbano constitui um centro de serviços coletivos para uma determinada região e configura, em função das distintas complexidades incorporadas nos processos produtivos, uma rede urbana hierarquizada que conforma, por sua vez, um sistema de cidades em escalas diversas e muitas vezes sobrepostas. Neste as- pecto, a saúde adquire papel crítico como atividade de consumo coletivo, organizada no território em função da disponibilidade de oferta em vários níveis de complexidade.

Um segundo aspecto, em consonância com a Teoria dos Lugares Centrais ${ }^{15}$, é a organização dos serviços de saúde e como estes podem atuar na definição dos limites para a configuração de uma região e uma rede de cidades. Isto se explica pela relação de um centro urbano com seu entorno, em que se estabelece o limite crítico relacionado à existência, ou não, de um nível mínimo de aglomeração populacional e de demanda que torne racional a oferta dos serviços em uma determinada cidade, considerando a economia de escala. No outro extremo, o alcance atingido por um centro urbano, e a sua inserção na rede, depende da distância que é possível percorrer para ter acesso a determinados serviços essenciais. Quanto maior o nível de complexidade, maior tende a ser a região de influência do centro urbano e a distância em que as pessoas precisam e se dispõem a percorrer.

$\mathrm{Na}$ realidade, a estruturação da rede de saúde depara-se com o desafio de articular diferentes localidades que, pelo grau de concentração dos serviços urbanos ante a sua complexidade, formam uma rede e um espaço ou região de saúde. A sustentabilidade dessas regiões demanda ainda maior equilíbrio e articulação entre as políticas sociais e econômicas, chamando a atenção para as consequências de quando as demandas sociais deixam de coincidir com o mapa de investimentos público e privado ${ }^{16}$, e enfatizandose, assim, o papel do Estado. É possível, dessa forma, definir diferentes tipologias de cidades pela abrangência dos serviços que prestam, indo de atividades estruturadas em nível local (como a atenção primária) até o nível macrorregional ou mesmo nacional (como os centros especializados de alta complexidade).

Assim, apreende-se que a regionalização da saúde pode seguir proximamente e, ao mesmo tempo, ser um elemento indicativo para a regionalização do desenvolvimento e do planejamento nacional, captando a intensidade das relações de troca que estruturam a rede de serviços. Por sua vez, em um movimento mais político e estratégico, a transformação da organização da rede de saúde também pode ser um elemento indutor de novas regionalizações que permitam atenuar a iniquidade no que toca a distribuição de renda e o dinamismo econômico, evidenciando a natureza endógena da relação entre saúde e desenvolvimento ${ }^{17}$. 


\section{Descentralização e regionalização da política de saúde}

Demonstradas as diversas associações entre os campos da saúde e desenvolvimento, importa avaliar a virtuosidade, ou não, desta relação no Brasil. Com o intuito de se refletir sobre os desafios a serem enfrentados pela saúde como componente estruturante de um novo modelo de desenvolvimento nacional, há que se analisar o formato e efetividade da regionalização da saúde no Brasil.

Na sua concepção, o Sistema Único de Saúde (SUS) brasileiro associa a perspectiva territorial à diretriz da descentralização, por meio da estratégia de regionalização das ações e serviços de saúde ${ }^{18-19}$. Configura-se, assim, como um projeto de organização do sistema de saúde que deve ser, ao mesmo tempo, unificado, descentralizado e hierarquizado em todo o território nacional, atendendo à diversidade regional do país. Este modelo tem como objetivo maior a expansão do acesso à saúde (universalidade e integralidade), a atenção às necessidades locais, a participação social e o uso eficiente dos recursos.

Entretanto, o SUS, elaborado e institucionalizado no final da década de 1980, deparou-se com a complexidade do cenário político dos anos 90, quando se observou a inflexão do padrão de intervenção do Estado - e da própria condução da descentralização de encargos e recursos no país, com importantes implicações para as relações federativas.

A experiência brasileira revela a complexidade de consolidar uma política nacional de saúde em um país imenso, desigual, com um sistema político federativo, sendo esta continuamente tensionada por diversos obstáculos estruturais e conjunturais ${ }^{20}$. Por sua vez, a análise da trajetória da descentralização da saúde reflete as contradições e os impasses na construção do enfoque regional desta política que tem como questão central a organização das ações e serviços no território.

Neste sentido, há que se ressaltar cinco aspectos. O primeiro refere-se à estratégia da descentralização da saúde, que não foi pensada no contexto de um modelo de desenvolvimento para o país. Pelo contrário, a agenda desenvolvimentista saiu do cenário nacional e foi substituída pelo debate da redemocratização do Estado nos anos 80 e pela busca de estabilização e controle da moeda nos anos 90. A hipótese defendida, no bojo da descentralização, era de que o binômio diminuição do Estado e a descentralização da gestão dos serviços públicos levaria, necessariamente, ao aumento da efetividade da atuação do Estado na provisão de bens e serviços essenciais prestados para a população. Na prática, entretanto, a descentralização adequou-se, essencialmente, à tendência hegemônica e liberal, que contextualizava a prioridade de enxugamento do Estado e de estabilização macroeconômica.

$\mathrm{O}$ segundo aspecto a ser analisado refere-se ao fato de que o território não tenha se apresentado como objeto principal de análise e planejamento para as diferentes áreas do governo durante a década de 1990. Logo, no processo de descentralização em saúde, a dimensão territorial não foi incorporada à formulação de políticas, valendo citar algumas iniciativas recentes direcionadas para regiões específicas (Saúde na Amazônia, Sis-Fronteiras e RIDE-DF). Como resultado, há uma fragilidade da lógica territorial na formulação de políticas públicas, com escassez de estratégias e instrumentos para atender aos objetivos da redução da iniquidade social e territorial; e os existentes não se articulam entre si.

Assim, o terceiro ponto marcante é que a descentralização dissociou-se de um projeto de regionalização nacional, e as experiências de organização territorial das ações e serviços de saúde foram limitadas, resultando em um sistema ineficiente e pouco sustentável. As propostas de regionalização tiveram início tardio, após sucessivos momentos de descentralização, que ocorreram sob forte indução e regulação federal, essencialmente por meio de normas operacionais básicas e de assistência do SUS; além de numerosas portarias editadas a cada ano pelas diversas áreas do Ministério da Saúde e demais entidades federais da saúde. Estas associavam-se, em geral, a mecanismos financeiros de incentivo ou inibição de políticas e práticas pelos gestores de outras esferas de governo e prestadores de servi$\operatorname{ços}^{21}$. No entanto, dada a complexidade e o contexto citado, houve dificuldades em traçar estratégias políticas que garantissem a integração das ações e serviços de diferentes níveis de complexidade, situadas em distintos espaços geográficos e territórios político-administrativos, ou seja, prejudicou-se o estabelecimento de uma racionalidade sistêmica no âmbito do SUS ${ }^{22}$.

Na prática, a descentralização na saúde seguiu um movimento mais geral de ênfase nos municípios na condução da política (quarto aspecto). Observou-se o esvaziamento do papel dos estados, dificultando, ou mesmo impedindo em alguns casos, a coordenação e o planejamento de todo o sistema a partir de uma lógica territorial. 
O processo de municipalização, por um lado, permitiu a instituição do SUS a partir da ampliação do acesso à saúde, por outro provocou a criação de milhares de "sistemas locais isolados". Os governos locais assumiram a responsabilidade pela provisão de serviços de saúde, num contexto em que a maioria dos municípios apresentava pequena base populacional e limitada capacidade institucional, o que prejudicou a função de planejamento regional.

O quinto aspecto é que na saúde a concepção de regionalização tem se restringido às questões relativas à organização da rede de serviços no âmbito intraestadual, sem a incorporação de uma lógica territorial mais abrangente e a articulação com outras esferas da política pública ${ }^{23}$. O território em saúde tem sido tratado no âmbito da política de saúde de forma estanque, numa concepção rígida de fluxos e organizações, prejudicando não somente seu objetivo primeiro, da prestação efetiva da saúde, como também a constituição de um sistema que minimize e contrarie tendências perversas de concentração espacial e consequente exclusão social.

Uma primeira mudança nesta concepção se apresentou no contexto do Pacto pela Saúde de $2006^{24}$, que estabeleceu a liberdade de adequação de estratégias às diferentes realidades, possibilitando a constituição de novas centralidades e novos arranjos de gestão na organização do modelo assistencial. Há nesse contexto uma mudança na definição de região com a proposição de diferentes desenhos de regiões de saúde (entendidas como recortes de espaços geográficos intramunicipais, intraestaduais, interestaduais e fronteiriças), implicando o reconhecimento das especificidades e do arranjo político-institucional pactuado. Ainda no contexto do Pacto, assume-se que a região deve atender a critérios que propiciem resolutividade ao território, com suficiência em atenção básica e parte da média complexidade.

Contudo, mesmo que a questão territorial tenha tido um novo tratamento no Pacto pela Saúde, está implícita nessas diretrizes uma concepção de regionalização que ainda carrega consigo dois pressupostos básicos: (1) o da garantia do acesso aos serviços de saúde, buscando atender às situações diversas com uma melhor e mais rápida resposta aos desejos e necessidades dos usuários; e (2) o da implantação racional dos recursos de saúde, que devem ser organizados segundo uma lógica hierárquica, com o objetivo de otimizar os gastos com base nos ganhos de eficiência decorrentes da articulação das vantagens da provisão local com economia de escala nas ações e serviços prestados. Um olhar um pouco mais atento permite ponderar que os pressupostos do Pacto não poderão avançar substancialmente sem nova repactuação dos critérios de repasse de recursos; sem considerar a lógica regional que precisa ser planejada e pactuada entre as três esferas de governo, com recuperação do papel das unidades federadas neste processo; e sem um maior aporte de recursos que responda pela necessária desconcentração da infraestrutura de bens e serviços de saúde.

Tal concepção, que está atrelada à definição tradicional de território adotada na saúde pública - compreendido como uma área geográfica delimitada na qual uma população está referida -, dificulta a construção de políticas regionais integradas. Isso porque não considera a dinâmica dos territórios (em seus aspectos econômico, político, cultural e social), o fluxo das populações ${ }^{25}$ e os condicionantes macroestruturais que cristalizam e reproduzem a iniquidade.

Há um equilíbrio ainda a ser alcançado entre a descentralização dos serviços de saúde e a concentração tanto nos níveis intermediários, micro ou mesorregionais, quanto nos centrais, macrorregionais ou nacionais. A presença de múltiplas escalas exige que o debate de uma política regional seja capaz de articular a territorialização das ações às especificidades de cada campo de atuação da saúde e suas lógicas internas, bem como aos fluxos e organizações dos espaços. Ou seja, exige amadurecimento da articulação dos atores, efetiva coordenação e aumento do aporte de recursos.

\section{A evolução dos investimentos federais em saúde}

A constatação do caráter crítico da relação entre saúde e desenvolvimento, em especial na sua dimensão espacial (dadas as características brasileiras), remete à importância de se avaliar a estrutura e a origem do financiamento da saúde, assim como a caracterização da sua evolução recente no orçamento do Ministério da Saúde brasileiro, uma vez que esta exemplifica dificuldades diversas nesse âmbito.

A análise dos dispêndios federais da saúde indica a pouca importância dos investimentos no período de 1997 a 2004, conforme pode-se constatar no Gráfico 1. De fato, a maior parte dos recursos federais da saúde é destinada à manutenção da rede já existente, por meio do pagamento de serviços prestados ou das transferênci- 
as intergovernamentais para estados e, principalmente, para os municípios ${ }^{26}$. Isto indica, entre outras coisas, a tendência à manutenção do direcionamento dos fluxos financeiros do SUS, que tendem a se direcionar para os loci onde já há infraestrutura instalada e mão de obra qualificada, reforçando e mantendo as disparidades regionais observadas no âmbito deste Sistema. Ademais, com exceção de 2001, a participação proporcional dos investimentos nas despesas federais totais em saúde esteve sempre abaixo de 5\% nos anos analisados, o que aponta para a limitação da reversão desta tendência concentradora.

Nos períodos críticos para o financiamento da saúde, quando se observam oscilações importantes nos gastos federais com ações e serviços de saúde, como entre 1995 a 1998 e em 2003, a participação dos investimentos nas despesas federais cai de forma significativa. As quedas observadas apontam que os investimentos foram objeto de cortes orçamentários e indicam a fragilidade financeira dos projetos conduzidos nacionalmente.
Além disto, quando se avalia a composição deste investimento, observa-se que, em 2001, ano que os investimentos alcançaram a maior proporção das despesas orçamentárias do Ministério da Saúde $(8,7 \%)$, os gastos com saneamento básico representaram cerca de $60 \%$ do total de investimentos federais em saúde (Gráfico 2). Na realidade, observa-se que os projetos de saneamento básico respondem por parcelas significativas dos investimentos do Ministério da Saúde de 1997 a 2005, se comparados aos recursos destinados à infraestrutura do SUS (equipamentos, reformas e construção, programas de capacitação de recursos humanos e desenvolvimento institucional).

Ainda no Gráfico 2 pode-se verificar a relevância do papel que as emendas parlamentares desempenham na obtenção de receitas para os investimentos, voltados tanto para os serviços de saúde como para o saneamento básico, sob responsabilidade do Ministério da Saúde. Isso aponta para a baixa governabilidade do Executivo Federal no destino final dos investimentos realizados em saúde, em especial ao se considerar a diversi-

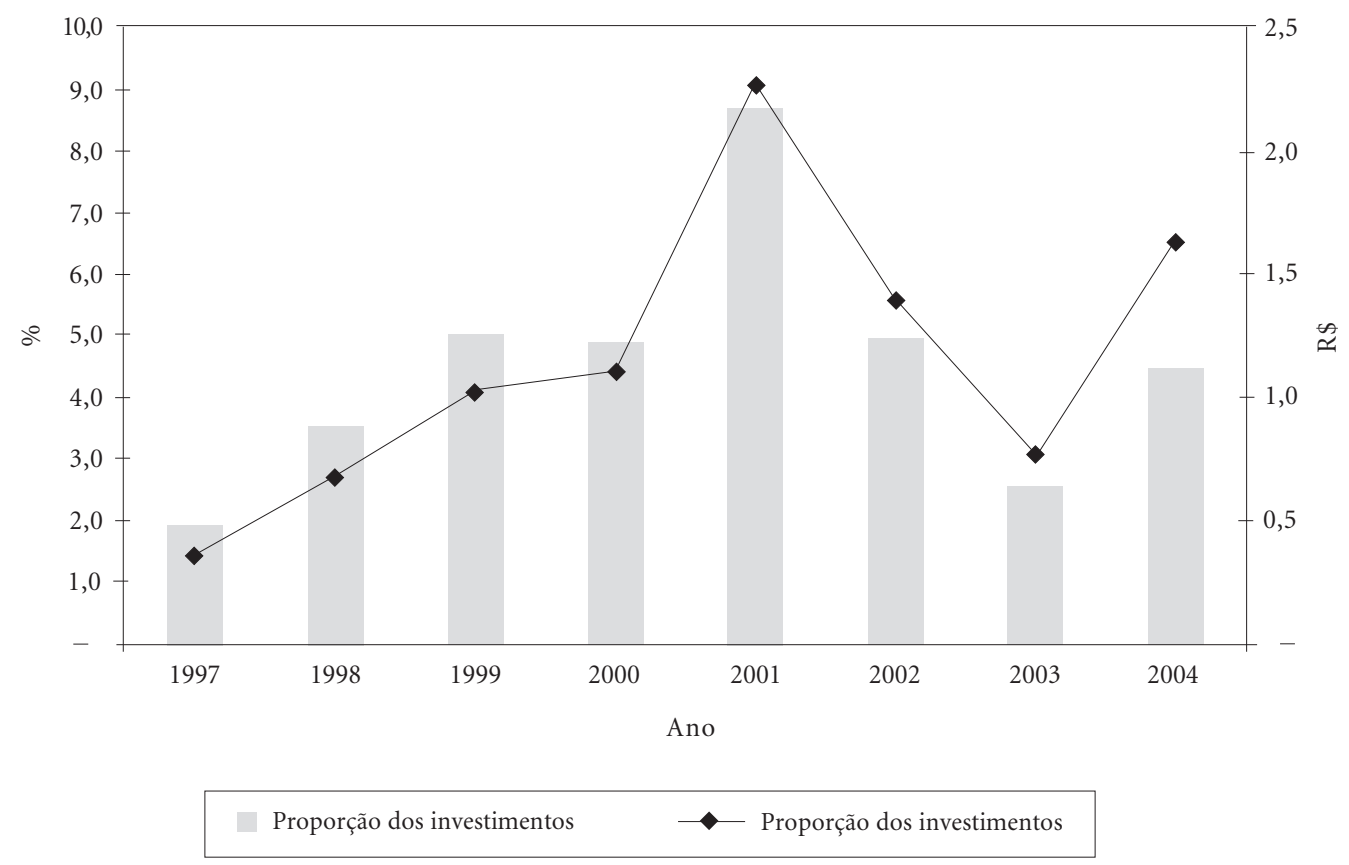

Gráfico 1. Evolução da participação (\%) e do valor dos investimentos (em bilhões de reais) no orçamento do Ministério da Saúde - Brasil, 1997-2004. 
Gráfico 2. Distribuição proporcional dos componentes das despesas orçamentárias do Ministério da Saúde com investimentos e participação (\%) das emendas parlamentares como fonte de receitas para os investimentos realizados - Brasil, 1997-2005.

Fonte: Ministério da Saúde - SE/SPO/Coordenação Geral de Orçamento e Finanças e Coordenação de Acompanhamento e Avaliação. Elaboração dos autores.

dade de propostas e fatores que condicionam as negociações relativas ao Orçamento no Congresso Nacional que, muitas vezes, colidem com o desenho regional e os objetivos da política de saúde. Além disso, as emendas têm caráter irregular e são consideradas pouco estruturantes para o sistema de saúde, pois, na relação do Executivo com o Legislativo, têm sido utilizadas mais como um instrumento para aumento da governabilidade do que da equidade ${ }^{27-28}$.

Em resumo, a combinação da baixa proporção de investimentos com a pouca governabilidade sobre eles aponta inequivocamente a limitação do governo federal em estabelecer regiões de saúde coerentes com os preceitos do SUS e com este relacionamento intrínseco entre saúde e desenvolvimento.

Adicione-se ainda o fato de que embora os dados fornecidos não permitam identificar com clareza a participação dos empréstimos adquiridos junto a bancos internacionais como fonte de receitas, sabe-se que nesse período vigoraram na saúde grandes projetos de investimentos financiados com recursos do Banco Mundial e do Banco Interamericano de Desenvolvimento. Quanto maior a participação dessas fontes internacionais - orientados para projetos que não necessariamente se coadunam com as prioridades de alocação de recursos do SUS - na composição total dos investimentos, maior tende a ser a atomização das iniciativas. Há estudos que justamente evidenciam problemas e lacunas relacionados a esses projetos, devido à insuficiência dos mecanismos de planejamento regional dos investimentos que acabam ocasionando alocação pouco equitativa dos recursos e à inadequada previsão de critérios e ações voltadas para a sustentabilidade dos projetos implantados ${ }^{29}$. 
Quanto à distribuição dos investimentos realizados pelo Ministério da Saúde nas macrorregiões brasileiras, as regiões Nordeste e Sudeste são as que obtiveram, proporcionalmente, volume mais expressivo de investimentos, no período compreendido entre 1999 e 2005. Entretanto, conforme observado no Gráfico 3, se considerados em valores per capita, os investimentos acabaram beneficiando principalmente o Norte e o Centro-Oeste em todo o período analisado, com exceção de 2001. Neste ano, a maior proporção dos investimentos no Norte e no Nordeste indica a priorização dos projetos de saneamento básico no âmbito do Projeto Alvorada.

Em uma primeira leitura do corte regional desses investimentos, nota-se um esforço de superação das desigualdades em saúde nos últimos anos, em escala macrorregional, a partir do privilégio de regiões mais carentes de oferta e cobertura de ações e serviços de saúde. Os resultados dos investimentos realizados, entretanto, permanecem insatisfatórios, o que se pode aferir pela qualidade e disponibilidade dos serviços nas regiões menos privilegiadas. Ademais, tais aportes de recursos não parecem atender a uma orientação estratégica e, muito menos, a uma política deliberada de atenuação das desigualdades regionais. Na prática, os investimentos federais em saúde caracterizam-se pela pulverização das ações e por uma visão fragmentada do território brasileiro. Com isto, a situação de rigidez na distribuição espacial da oferta de serviços tende a perpetuar as desigualdades na alocação dos recursos de custeio, na utilização dos serviços e nos indicadores de saúde.

\section{Considerações finais}

Este artigo trata da existência de um descompasso expressivo entre a evolução das bases políticoinstitucionais do sistema de saúde brasileiro e sua configuração no território. Observam-se, por um lado, importantes avanços a partir da adoção de uma concepção abrangente de saúde no texto constitucional vinculada à equidade em sua dimensão social e territorial. Seguindo esta concepção, configura-se um sistema nacional organizado em bases federativas, que possui, ante outras áreas de intervenção, um grau elevado de institucionalização e de participação da sociedade civil, incorporando, inclusive, a regionalização como

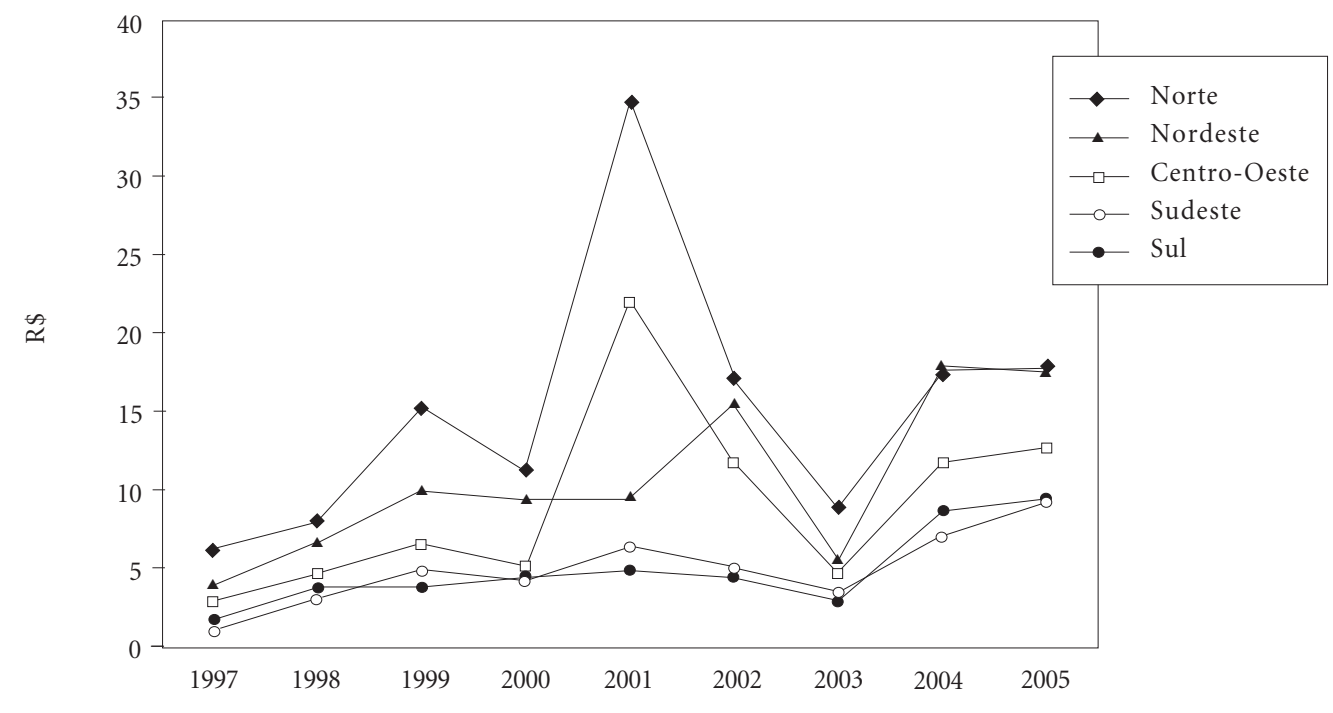

Gráfico 3. Investimentos do Ministério da Saúde em valor per capita (R\$) por macrorregião - Brasil, 19972005.

Fonte: Ministério da Saúde - SE/SPO/Coordenação Geral de Orçamento e Finanças e Coordenação de Acompanhamento e Avaliação. Elaboração dos autores. 
um dos eixos das estratégias do Governo Federal para o SUS. No entanto, vigora um padrão de financiamento das ações em geral e do investimento, em particular, que tem se mostrado incapaz de alterar o quadro de iniquidade territorial tanto pela insuficiência dos recursos para investimento quanto por sua orientação sem uma perspectiva mais estratégica, a despeito da obtenção de alguns avanços localizados.

Esta situação extravasa o âmbito setorial específico, já que a saúde é, ao mesmo tempo, parte do sistema de proteção social e um fator essencial que condiciona o desenvolvimento e a própria dinâmica regional, com impacto sobre a renda, o emprego, os investimentos e as inovações estratégicas no âmbito da revolução tecnológica em curso. Ou seja, há que se atentar que a cadeia de determinação não atua somente no sentido do desenvolvimento para a saúde, mas também das condições de saúde para o desenvolvimento nacional e das regiões e territórios em diversas escalas. Esta associação, que situa a saúde não somente como consequência, mas também como portadora de desenvolvimento, ainda não parece ter sido explorada no âmbito da retomada do planejamento estratégico nacional e da definição do novo padrão de desenvolvimento nacional. Ignorá-la pode trazer sérios entraves tanto para a saúde quanto para o projeto de desenvolvimento em execução.

Cabem, assim, algumas considerações quanto à relação entre a saúde e o padrão nacional de desenvolvimento com foco na dimensão territorial, visando contribuir para a reversão do quadro de iniquidade existente no Brasil.

Se for adotado o vínculo entre saúde e desenvolvimento como ponto de partida, a primeira questão que emerge é a insuficiência do gasto nacional para viabilizar uma lógica regional de atenuação da desigualdade. A transformação da configuração territorial da saúde requer uma ampliação do esforço público, uma vez que a estrutura existente impõe um custo de manutenção (mesmo nas despesas com capital) que, em si, já superam o orçamento disponível. Para tornar viável um progressivo processo de mudança na configuração regional do sistema de saúde, é necessário assegurar estratégias que garantam um aumento do montante de recursos e a estabilidade das fontes de financiamento setorial. Apenas com este esforço político é possível considerar e implementar critérios estratégicos adicionais à descentralização do sistema que, até o momento, tem se restringido à lógica administrativa da racionalidade nas despesas e da garan- tia do acesso. Sem esta perspectiva, a "eficiência" estática do sistema pode comprometer sua transformação e eficiência dinâmica.

Os investimentos do Governo Federal com as despesas de capital na rede de atenção à saúde, além de serem insuficientes, mostram-se fragmentados, o que limita ou impede uma orientação estratégica deles. Assim, não surpreende que os dados de distribuição regional representem informações ex-post de gastos com capital sem significado estratégico sobre a evolução e configuração da rede de saúde, refletindo projetos específicos, apoio parlamentar (na ótica da governabilidade) ou acordos internacionais. Dessa forma, a distribuição regional dos investimentos em geral não segue estratégias de longo prazo e sua efetividade é limitada pela fragmentação e porte de recursos.

Este modo precário de orientação dos investimentos em saúde, comum a diversas políticas nacionais na América do Sul, talvez seja o fator mais crítico para articular a lógica da saúde com a do desenvolvimento em bases territoriais. Sem a disponibilidade de recursos numa magnitude mínima e com sua utilização fragmentada e pouco estratégica, emerge como critério dominante de alocação o peso da capacidade já instalada e sua distribuição iníqua no território. Ou seja, o ciclo vicioso do direcionamento do fluxo de capitais é reforçado, levando a que um grande contingente seja alijado de suas condições mínimas, e constitucionalmente garantidas, de cidadania.

A estruturação da rede de serviços de saúde constitui um fator central para se pensar a rede de cidades e a territorialização do planejamento e da intervenção pública ${ }^{12}$. A rigidez da estrutura de oferta existente é, portanto, um fator crítico para a regionalização e, consequentemente, a busca de uma maior equidade tanto para o setor saúde quanto para a estratégia de atenuação da desigualdade regional no território, visando à sustentabilidade do desenvolvimento nacional. Fica evidenciado, segundo a perspectiva que enfatiza o papel da organização da rede de serviços para a estruturação regional, o vínculo da saúde com os processos de desenvolvimento, e seu impacto sobre a organização espacial da sociedade brasileira e os processos endógenos de acumulação de capital baseados na geração e disseminação de inovações no território.

Enfatiza-se, à guisa de conclusão, que tanto o país, de forma geral, quanto o setor da saúde, em particular, carecem de uma perspectiva estratégica, teórica e política, que incorpore a região em suas diferentes escalas na busca de equidade, 
superando uma visão meramente administrativa de organização da rede. Entende-se que este papel depende de uma visão nacional do desenvolvimento regional e das desigualdades existentes mesmo no interior das regiões mais desenvolvidas, sendo esta uma atribuição indelegável da esfera federal de governo.

Na perspectiva teórica apresentada, emerge o desafio para a transformação progressiva de um sistema e de uma rede de saúde visando à equidade não apenas do ponto de vista reativo, ligado à provisão de condições melhores para as regiões menos aquinhoadas, mas fundamentalmente tomando a saúde como uma área que possui impactos diretos e indiretos na organização do território e na dinâmica - local e regionalizada - de inovação de diversos setores de atividade (incluindo os serviços e a indústria). Isso porque o sistema permite estimular os investimentos e, portanto, a geração de renda, emprego e a emergência de trajetórias regionais de desenvolvimento em diversas escalas.

Assim, a área da saúde, que inclui a produção articulada de bens e serviços, também deve ser apreendida como um sistema de inovação e sua configuração espacial pode ser uma base para o desenvolvimento de sistemas e arranjos produtivos locais, permitindo articular a lógica do bemestar com a lógica do desenvolvimento econômico ${ }^{6}$. De forma análoga, a falta de coordenação dos diversos interesses estratégicos mobilizados pela saúde (geração de tecnologia de ponta e inovação) ocasiona, em ambiente globalizado, à verticalização, e ao agravamento consequente, das disparidades regionais e sociais ${ }^{30}$.

Sugere-se pensar a orientação da configuração espacial do sistema de saúde (e, portanto, dos investimentos) que, adicionalmente à lógica organizacional e de acesso, possa introduzir uma racionalidade vinculada ao desenvolvimento na sua dimensão territorial. Para tanto, torna-se necessário fortalecer uma visão da saúde que privilegie seu vínculo com o desenvolvimento como fator essencial de cidadania e equidade e como fonte de expansão econômica do país e de suas regiões e territórios. Tal enfoque se inscreve num esforço analítico e político na direção de consolidar uma abordagem de economia política da saúde como contraponto ao pensamento neoclássico hegemônico, que se manifesta muito pragmaticamente nas ações e nos padrões de intervenção em saúde.
Essa perspectiva traz em seu bojo o desafio da intersetorialidade, situando a saúde no âmago do padrão nacional de desenvolvimento. E é justamente este o grande desafio: o de promover a incorporação mais ampla da saúde na estratégia nacional de desenvolvimento como uma frente de expansão de outro tipo de capitalismo no Brasil vinculado à própria estruturação, ainda que tardia e peculiar, de um Estado de Bem-Estar que se assente, simultaneamente, na busca de equidade e em uma economia nacional forte, dinâmica, competitiva. Do ponto de vista específico da área da saúde, cabe também uma ruptura que permita sair do insulamento que ainda a caracteriza, incorporando a estratégia nacional em suas propostas de regionalização, sob pena de as apostas efetuadas não encontrarem condições concretas para se efetivarem.

\section{Colaboradores}

CAG Gadelha, CV Machado, LD Lima e TWF Baptista participaram igualmente de todos os momentos da concepção, elaboração, análise dos dados, redação e revisão do artigo.

\section{Agradecimentos}

Aos funcionários do Ministério da Saúde pelo fornecimento de dados. Ao Centro de Gestão e Estudos Estratégicos (CGEE) e ao Ministério do Planejamento, Orçamento e Gestão pelo apoio no âmbito do "Estudo da Dimensão Territorial do PPA". A Laís Costa, doutoranda da Escola Nacional de Saúde Pública Sergio Arouca da Fundação Oswaldo Cruz (Ensp/Fiocruz), pelos comentários e contribuição na sistematização final deste artigo. CV Machado, LD Lima e TWF Baptista foram apoiadas pelo Conselho Nacional de Desenvolvimento Científico e Tecnológico (CNPq) e pela Fundação de Amparo à Pesquisa do Estado do Rio de Janeiro (Faperj). 


\section{Referências}

1. Sen A. Desenvolvimento como liberdade. São Paulo: Companhia das Letras; 2000.

2. Sen A. Teorías del desarrollo a principios del siglo XXI. In: Castellano FL, coordenador. Desarrollo: crônica de un desafio permanente. Granada: Universidad de Granada; 2007. p. 247-274.

3. Oliveira F. As contradições do ão: globalização, nação, região, metropolização. In: Diniz CC, Crocco M, organizadores. Economia regional e urbana: contribuições teóricas recentes. Belo Horizonte: Editora UFMG; 2006. p. 33-60.

4. Buss PM, Pellegrini Filho A. Iniqüidades em saúde no Brasil, nossa mais grave doença: comentários sobre o documento de referência e os trabalhos da Comissão Nacional sobre Determinantes Sociais da Saúde. Cad Saude Publica 2006; 22(9):2005-2008.

5. Figueiredo L. As novas teorias do crescimento econômico: contribuições para a política regional. In: Diniz CC, Crocco M, organizadores. Economia regional e urbana: contribuições teóricas recentes. Belo Horizonte: Editora UFMG; 2006. p. 121-142.

6. Gadelha CAG. O complexo industrial da saúde e a necessidade de um enfoque dinâmico na economia da saúde. Cien Saude Colet 2003; 2(8):521-535.

7. Viana ALA, Elias PEM. Saúde e desenvolvimento. Cien Saude Colet 2007; 12(Supl.):1765-1777.

8. Freeman R, Moran M. A saúde na Europa. In: Negri B, Viana ALA, organizadores. O SUS em dez anos de desafio. São Paulo: Sobravime/Cealag; 2002. p. 45-64.

9. Machado CV, Lima LD, Baptista TWF. Configuração institucional e papel dos gestores no Sistema Único de Saúde. In: Matta GC, Pontes ALC, organizadores. Políticas de saúde: a organização e a operacionalização do Sistema Único de Saúde. Rio de Janeiro: EPSJV/Fiocruz; 2007. p. 139-162.

10. Gadelha CAG, Costa LC. Integração de fronteiras: a saúde no contexto de uma política nacional de desenvolvimento. Cad Saude Publica 2007; 23(Supl.2):214-226.

11. Draibe SM. Coesão social e integração regional: a agenda social do Mercosul e os grandes desafios das políticas sociais integradas. Cad Saude Publica 2007; 23(Supl.2):174-183.

12. Diniz CC, Crocco M. Introdução - bases teóricas e instrumentais da economia regional e urbana e sua aplicabilidade ao Brasil: uma breve reflexão. In: Diniz CC, Crocco M, organizadores. Economia regional e urbana: contribuições teóricas recentes. Belo Horizonte: Editora UFMG; 2006. p. 9-32.

13. Albuquerque EM, Cassiolato JE. As especificidades do Sistema de Inovação do Setor Saúde: uma resenha da literatura como introdução a uma discussão sobre o caso brasileiro. São Paulo: USP; 2000. (Estudos FeSBE I).
14. Brandão CA, Costa EJM, Alves MAS. Construir o espaço supralocal de articulação socioprodutiva e das estratégias de desenvolvimento: os novos arranjos institucionais. In: Diniz CC, Crocco M, organizadores. Economia regional e urbana: contribuições teóricas recentes. Belo Horizonte: Editora UFMG; 2006. p. 195-224.

15. Lemos MB. Desenvolvimento econômico e a regionalização do território. In: Diniz CC, Crocco M, organizadores. Economia regional e urbana: contribuições teóricas recentes. Belo Horizonte: Editora UFMG; 2006. p. 173-194.

16. Silveira ML. Ao território usado a palavra: pensando princípios de solidariedade socioespacial. In: Viana AL, Ibañez N, Elias PEM, organizadores. Saúde, desenvolvimento e território. São Paulo: $\mathrm{Hu}-$ citec; 2009. p. 127-150.

17. Gadelha CAG. Desenvolvimento e saúde: em busca de uma nova utopia. Rev Saúde em Debate 2005; 29(71):326-337.

18. Brasil. Constituição da República Federativa do Brasil: promulgada em 5 de outubro de 1988. Brasília: Senado Federal; 1988.

19. Brasil. Lei no 8.080, de 19 de setembro de 1990. Lei Orgânica da Saúde Institui o Sistema Único de Saúde. Diário Oficial da República Federativa do Brasil 1990; 20 set.

20. Levcovitz E, Lima LD, Machado CV. Política de saúde nos anos 90: relações intergovernamentais e papel das normas operacionais básicas. Cien Saude Colet 2001; 6(2):269-291.

21. Machado CV. O modelo de intervenção do Ministério da Saúde nos anos 90. Cad Saude Publica 2007; 13(9):2113-2126.

22. Viana ALA, Lima LD, Oliveira RG. Descentralização e federalismo: a política de saúde em novo contexto - lições do caso brasileiro. Cien Saude Colet 2002; 7(3):493-507.

23. Viana ALA, Machado CV, Baptista TWF, Lima LD, Mendonça MHM, Heimann LS, Luiza S, Albuquerque MV, Iozzi FL, David VC, Ibañez P, Frederico S. Sistema de saúde universal e território: desafios de uma política regional para a Amazônia Legal. Cad Saude Publica 2007; 23(Supl.2):117-131.

24. Brasil. Ministério da Saúde. Secretaria Executiva. Departamento de Apoio à Descentralização. Pactos pela Vida, em Defesa do SUS e de Gestão: diretrizes operacionais. Brasília: Ministério da Saúde; 2006. (Série Pactos pela Saúde, v.1).

25. Santos M. A natureza do espaço, técnica e tempo, razão e emoção. São Paulo: Hucitec; 1996.

26. Lima LD. Federalismo, relações fiscais e financiamento do Sistema Único de Saúde: a distribuição de receitas vinculadas à saúde nos orçamentos municipais e estaduais. Rio de Janeiro: Editora do Museu da República; 2007. 
27. Oliveira PTR. O Sistema Único de Saúde, descentralização e a desigualdade regional: um enfoque sobre a região da Amazônia Legal [tese]. Rio de Janeiro: Escola Nacional de Saúde Pública Sergio Arouca, Fundação Oswaldo Cruz; 2005.

28. Pereira C, Mueller B. Comportamento estratégico em presidencialismo de coalizão: as relações entre Executivo e Legislativo no Presidencialismo brasileiro. Dados 2002; 45(2):265-301.

29. Pessôa LR. Mergulho em Montes Claros: desafios da alocação de recursos na rede SUS [tese]. Rio de Janeiro: Escola Nacional de Saúde Pública Sergio Arouca, Fundação Oswaldo Cruz; 2005.

30. Santos M. Da totalidade ao lugar. São Paulo: Editora da Universidade de São Paulo; 2008.

Artigo apresentado em 26/08/2009

Aprovado em 21/05/2010

Versão final apresentada em 30/06/2010 